\title{
LAS MORATORIAS CIENTÍFICAS EN EL CONTEXTO DE LA DECLARACIÓN UNIVERSAL SOBRE BIOÉTICA Y DERECHOS HUMANOS
}

\author{
SCIENTIFIC MORATORIES IN THE CONTEXT \\ OF THE UNIVERSAL DECLARATION \\ ON BIOETHICS AND HUMAN RIGHTS
}

\author{
Manuel Jesús López Baroni \\ Universidad Pablo de Olavide - Sevilla
}

Fecha de recepción: 18-2-21

Fecha de aceptación: 1-9-21

Resumen: En 1975, la Conferencia de Asilomar inauguró una forma de normatividad que ha sido en general minusvalorada por los juristas: la declaración de una moratoria científica de carácter voluntaria, temporal y universal. Desde entonces, se han sucedido este tipo de declaraciones, aunque con desigual resultado. Su principal característica es que los científicos realizan un descubrimiento o innovación tecnocientífica cuyo alcance inmediato no pueden calibrar, en un contexto de anomia jurídica y de desconocimiento total y absoluto por parte de la sociedad y los poderes públicos. Pues bien, nos planteamos en qué medida el Derecho podría o debería receptar este tipo de declaraciones con objeto de que sean vinculantes, en concordancia con el contenido de la Declaración Universal sobre Bioética y Derechos Humanos de la UNESCO.

Abstract: In 1975, the Asilomar Conference inaugurated a form of regulation that has been generally underestimated by jurists: the declaration of a voluntary, temporary and universal scientific moratorium. Since then, these types of statements have occurred, although with uneven results. The main characteristic of these statements is that scientists make a techno-scientific discovery or innovation whose immediate scope they cannot calibrate, in a context of legal anomie and total and absolute ignorance on the part of society and public powers. Well, we wonder to what extent the law could or should accept this type of statement in order to make it binding, in accordance with the content of the Universal Declaration on Bioethics and Human Rights OfUNESCO.

ISSN: 1133-0937

DERECHOS Y LIBERTADES

DOI: https://doi.org/10.20318/dyl.2022.6522

Número 46, Época II, enero 2022, pp. 297-325 
Palabras clave: moratoria científica, fuentes del derecho, principios generales del Derecho, cuarta revolución industrial, tecnologías disruptivas

Keywords: scientific moratorium, sources of law, general principles of Law, fourth industrial revolution, disruptive technologies

\section{INTRODUCCIÓN}

En la Declaración Universal sobre Bioética y Derechos Humanos de la UNESCO se recoge lo siguiente:

"Preámbulo. Teniendo en cuenta los rápidos adelantos de la ciencia y la tecnología, que afectan cada vez más a nuestra concepción de la vida y a la vida propiamente dicha, y que han traído consigo una fuerte demanda para que se dé una respuesta universal a los problemas éticos que plantean esos adelantos. (...) Artículo 16 - Protección de las generaciones futuras. Se deberían tener debidamente en cuenta las repercusiones de las ciencias de la vida en las generaciones futuras, en particular en su constitución genética. Artículo 17 - Protección del medio ambiente, la biosfera y la biodiversidad. Se habrán de tener debidamente en cuenta la interconexión entre los seres humanos y las demás formas de vida, la importancia de un acceso apropiado a los recursos biológicos y genéticos y su utilización, el respeto del saber tradicional y el papel de los seres humanos en la protección del medio ambiente, la biosfera y la biodiversidad".

Pues bien, el reconocimiento de la celeridad con que avanza la tecnociencia, la preocupación por el medio ambiente y el temor subyacente por la forma en que podamos condicionar a las generaciones futuras, incluido su patrimonio genético, nos llevan a reflexionar sobre cuál debe ser la respuesta del Derecho ante eventos sorpresivos, inesperados y de potencial efecto global. En concreto, nos planteamos si, a la luz de los preceptos citados, deben ser vinculantes para los tribunales de justicia las moratorias científicas.

Para ello, analizaremos el siguiente supuesto de hecho: dado un determinado progreso tecnológico, la comunidad científica decide establecer una moratoria voluntaria, temporal y universal hasta que se calibren adecuadamente los riesgos inherentes a dicho avance. Si algún equipo de investigadores no respeta la moratoria, ¿se podría instar una acción judicial para que un tribunal bloqueara, e incluso sancionara, la ruptura de la moratoria?

Para poder responder a esta pregunta resulta necesario plantearse la naturaleza jurídica de una moratoria, esto es, en qué medida un acto consen- 
suado por la comunidad científica, cuyo grado de coercibilidad no supera el acuerdo moral, puede convertirse en una fuente del derecho vinculante, tribunales mediante y en un contexto de anomia jurídica, para toda la sociedad, justificado por riesgos impredecibles, globales y/o irreversibles.

Un posible medio para lograr que las moratorias sean obligatorias desde un punto de vista estrictamente jurídico es considerar que su declaración constituye un principio general del derecho, y por ende, universal, imperativa y no opcional. Para defender esta opción debemos estudiar, siquiera sea someramente, cómo la expresión "principio general del derecho" se ha empleado en otras situaciones para cubrir lagunas a la hora de enfrentarnos a situaciones potencialmente perturbadoras.

Para alcanzar una conclusión como la expuesta debemos analizar también variables no estrictamente jurídicas, tales como: a) la justificación y/o utilidad de las moratorias científicas; b) la singularidad tecnocientífica de nuestra época contemporánea y la celeridad con que avanza; c) la dificultad para valorar adecuadamente los riesgos reales de determinadas investigaciones; d) el vacío normativo existente ante las propuestas más atrevidas de la tecnociencia actual; e) el contexto ideológico (v. gr., aversión a los organismos modificados genéticamente) y religioso (v gr., rechazo de las investigaciones con células madre embrionarias) que frena injustificadamente los avances científicos; f) la potencial utilización espuria de las moratorias (v. gr., bloquear a la competencia; proteccionismo económico).

Con objeto de poder profundizar en estas cuestiones emplearemos el único material disponible, esto es, las moratorias, expresas o tácitas, efectivas o no, que se han propuesto en estas últimas décadas, en concreto, desde el inicio de la biotecnología moderna, allá por los años setenta del pasado siglo, hasta las del presente año.

La justificación última de este trabajo reside en la constatación de que vivimos un momento único en la historia de la tecnología, plagado de promesas, pero también de retos muy diferentes a los que hemos afrontado desde la primera revolución industrial. Sin duda, lograr que una propuesta científica, carente a priori de vocación jurídica, sea vinculante para los tribunales de justicia, plantea problemas técnicos formidables, como la jurisdicción competente, el cauce procesal o incluso los medios para hacer efectiva una hipotética resolución judicial. Aun así, estimo que la incertidumbre inherente a determinados experimentos exige medidas diferentes a las ya existentes, de forma que, sin detener el avance tecnocientífico, podamos ejercer un con- 
trol en tiempo real a determinadas investigaciones en aras de la seguridad colectiva.

\section{CARACTERÍSTICAS DE LAS MORATORIAS CIENTÍFICAS}

Dado que no existe un manual de instrucciones para este tipo de declaraciones, la única forma de examinar las características de las moratorias científicas es recopilar las propuestas en los últimos años, con independencia de si tuvieron realmente éxito (v. gr., si se paralizaron efectivamente las investigaciones), o incluso si estaban justificadas desde una perspectiva exclusivamente técnica (v. gr., requerimientos a los investigadores para que no hagan cosas imposibles desde el punto de vista de las leyes de la naturaleza que conocemos). Para ello, distinguiremos varios ítems de análisis:

\subsection{Justificación}

Las moratorias científicas se proponen en situaciones donde se produce un avance tecnocientífico cuyo alcance no puede ser valorado en ese momento, en un contexto de riesgos posibles, aunque improbables, y sin antecedentes conocidos que puedan servir de referencia.

La primera moratoria científica expresa se adoptó en 1975, en Asilomar, en los inicios de la biotecnología moderna, a raíz de la inserción de ADN de un virus procedente de un mono en una bacteria que está presente en todos los seres humanos. ${ }^{1}$ Aunque en realidad los experimentos se paralizaron antes de que se decretara, la moratoria duró tan solo seis meses; además, con el tiempo se demostró que el temor estaba injustificado. La última propuesta de moratoria formal se formuló en 2019, a raíz de la técnica de edición genómica CRISPR, que permite modificar la línea germinal humana, y ha sido un completo fracaso.

Entre una y otra, en menos de cincuenta años, se han efectuado varias propuestas, unas exitosas y otras irrelevantes, aunque no por ello arbitrarias. Lo que une estos requerimientos es que la comunidad científica desconoce qué va a suceder; la clase política vive ajena a los riesgos; la sociedad, aún más; y el ordenamiento jurídico carece de una respuesta pronta, proporcio-

1 Véase L. ALONSO, reseña del libro de J. Archibald, One Plus One Equals One. Symbiosis and the Evolution of Complex Life, Oxford University Press, Oxford, 2014, en Investigación y Ciencia, noviembre de 2014. 
nal y atinada, porque lógicamente nadie puede predecir los derroteros que tomarán determinadas líneas de investigación.

Por otra parte, se puede sostener que el hecho causal de una moratoria científica coincide con el supuesto fáctico de la aplicación del principio de precaución: el riesgo al cuadrado, esto es, el desconocimiento de lo que se desconoce. $^{2}$ Sin embargo, ambas figuras son diferentes, dado que mientras el principio de precaución tiene acogida en el ordenamiento jurídico, y de hecho, se aplica por los tribunales de justicia, las moratorias científicas son consideradas por la mayoría de los juristas como eventos ajenos al derecho.

\subsection{Casuística}

La casuística que puede generar una petición de moratoria es enorme debido a la amplia variabilidad de las disciplinas tecnocientíficas implicadas, de ahí la dificultad para establecer reglas generales. Aun así, podríamos distinguir varios supuestos posibles, lo que repercute a su vez en la plausibilidad de la aceptación de una moratoria.

2.2.1. Son casos donde se pretende "reescribir" la materia viva o la inerte. ${ }^{3}$ La acción, "reescritura", nos remite a una intervención sustancial en la materia que nos rodea. De hecho, las unidades susceptibles de ser intervenidas son especialmente sensibles, como sucede con los genes, los átomos o las neuronas. Sin embargo, a los entes materiales hay que añadir los inmateriales (v. gr., la información, los bits), dado que constituyen la base de la Inteligencia Artificial. Por último, resulta especialmente problemática la regulación de las entidades a medio camino entre lo tangible y lo intangible,

2 RAVETZ, en J. TABARA, D. POLO, L. LEMKOW, “Precaución, riesgo y sostenibilidad en los organismos modificados genéticamente", Política y Sociedad, vol 40, núm. 3, 2003, pp. 81-10.

3 Como sostienen con acierto Deplazes y Huppenbauer: "La emergencia de tecnologías innovadoras como la inteligencia artificial, la nanotecnología y la biología sintética está borrando las fronteras de nuestra distinción entre la materia viva y la no viva". A. DEPLAZES, M HUPPENBAUER, "Synthetic organism and living machines", Syst Synth Biol, núm. 3, 2009, pp. 55-63. Por nuestra parte, podríamos añadir que también es cada vez más difusa la línea que separa la curación de la mejora, a los animales de las cosas, y a su vez, a aquellos de los seres humanos. Sobre la interacción entre las tecnologías disruptivas, véase el informe norteamericano, M. ROCO, W. SIMS BAIMBRIDGE, NATIONAL SCIENCE FOUNDATION, Converging Technologies for Improving Human Performance, 2003, y el europeo, A. NORDMANN, Converging Technologies - Shaping the Future of European Societies, 2004.

ISSN: 1133-0937

DOI: https://doi.org/10.20318/dyl.2022.6522
DERECHOS Y LIBERTADES

Número 46, Época II, enero 2022, pp. 297-325 
como sucede con los genes, debido a que son entes materiales (v. gr. están compuestos de bases químicas), no están vivos (aunque son los "ladrillos" de los entes vivos), pero su relevancia ontológica viene dada por el lenguaje que codifican, esto es, por la "información", no por su constitución material (v. gr., las biopatentes representan la complejidad de tratar con estos entes biológicos).

2.2.2. Son situaciones donde pueden emerger entidades vivas o paranaturales por una modificación sustancial de las ya existentes (v. gr., virus modificados en laboratorio para que sean transmisibles entre humanos); por una recuperación de especies ya extintas, o al menos de sus neuronas (v. gr., mamuts, neandertales); por una descontextualización de las entidades vivas ya existentes (v. gr., orgánulos cerebrales humanos desarrollados en placas de Petri); por una mejora de los seres vivos ya existentes (v. gr., neuronas humanas trasplantadas o desarrolladas en animales que actúan de otra forma gracias a dicha interacción); por la creación de formas de vida de naturaleza diferente a la terrestre (v. gr., dextrógiras); por la emergencia de entidades cuasivivas (v. gr. una IA Fuerte); por la variación, no en el producto final, sino en la forma de su consecución (v. gr., recreación de un genoma humano sintético que podría dar lugar a un ser humano idéntico a nosotros); etcétera. ${ }^{4}$

4 Sobre la modificación del virus de la gripe aviar para que fuese transmisible entre seres humanos, véase R. FOUCHIER et al., "Restricted Data on Influenza H5N1 Virus Transmission", Science, vol 335, 10 February, 2012; sobre la creación de un genoma humano sintético, véase J. BOECKE et al., “The Genome Project-Write”, Science, 8 July, 2016; sobre la recuperación de especies extintas o la creación de formas de vida dextrógiras (la terrestre es levógira), véase G. CHURCH, Regenesis, How Synthetic Biology Will Reinvent Nature and Ourselves, Regis, 2011, y G. CHURCH, "Volved a la vida", Investigación y Ciencia, Octubre de 2013; sobre una Inteligencia Artificial Fuerte, véase COMISIÓN EUROPEA. Grupo Europeo sobre ética de la ciencia y las nuevas tecnologías, Statement on Artificial Intelligence, Robotics and 'Autonomous' Systems, 2018, y, COMISIÓN EUROPEA, Comunicación de la Comisión al Parlamento Europeo, al Consejo, al Comité Económico Social Europeo y al Comité de las Regiones, Inteligencia artificial para Europa, Bruselas, 25 de abril de 2018, y, en Estados Unidos, EXECUTIVE OFFICE OF THE PRESIDENT NATIONAL SCIENCE AND TECHNOLOGY COUNCIL COMMITTEE ON TECHNOLOGY, Preparing for the future of artificial intelligence, 2016, y también, Big Data: A Report on Algorithmic Systems, Opportunity, and Civil Rights. 2016; sobre el desarrollo de organoides cerebrales humanos, véase B. KOO, B. CHOI, H. PARK, K. YOON, "Past, Present, and Future of Brain Organoid Technology", Mol. Cells, vol. 42 núm. 9, 2019, pp. 617-627; sobre su imbricación con el cerebro de animales, véase A. POLLEN et al., "Establishing Cerebral Organoids as Models of Human-Specific Brain Evolution", Cell Stem 
En estos casos, el estatuto último de la entidad viva puede ser idéntico a las ya existentes (v. gr., creación de una célula totipotente humana de forma completamente artificial cuyo resultado es un ser humano. Su estatuto no sería el de un ente patentable -a pesar de alguna propuesta en este senti$\mathrm{do}^{5}$ - sino de identidad con los miembros de nuestra especie); la identidad, mediante analogía, con las especies ya existentes (v. gr., embarazar a una humana con el ADN sintetizado de un neandertal. ${ }^{6}$ En este caso, difícilmente se justificaría que el resultado no fuese equiparable al de un sapiens sapiens); la mejora de su estatuto moral y jurídico (v. gr., un animal mejorado cognitivamente, aunque no nos alcance en inteligencia $\left.{ }^{7}\right)$; su degradación moral y jurídica (v. g., la creación artificial de mamíferos inexistentes en la naturale$\mathrm{za}$, que se equipararían a las cosas a efectos jurídicos, como pueden ser las patentes o sus productos); ${ }^{8}$ o la creación de un estatuto moral y jurídico ad

Cell, February 07, vol. 176, 2019, pp. 743-756, y B. CAKIR et al., "Engineering of human brain organoids with a functional vascular-like system", Nature Methods, vol. 16, 2019, pp. 11691175; sobre el efecto de esta interacción con los animales y el debate sobre su estatuto posterior, véase I. CHEN et al, "Transplantation of Human Brain Organoids: Revisiting the Science and Ethics of Bran Chimeras", National Center for Biotechnology Information, vol 25, núm. 4, October 03, 2019, pp. 462-472, y FAHARANY et al., "The ethics of experimenting with human brain tissue", Nature, vol. 556, April 25, 2018, pp. 429-432; y, por último, sobre la utilización de organoides cerebrales de neandertal, véase J. COHEN, "Neanderthal brain organoids come to life", Science, vol 360, núm. 6395, Jun 22, 2018, p. 1284; G. O'REGAN, "Stem cells with Neanderthal genes developed into mini-brains" BIONEWS, July 02, 2018; y A. CLEBER et al., "Reintroduction of the archaic variant of NOVA1 in cortical organoids alters neurodevelopment", Science, vol 371, núm. 6530, February 12, 2021.

5 Véase la espinosa cuestión de a quién pertenece un genoma sintético en S. ADEE, "Analisys writing our genome", New Scientist, June 11, 2016.

6 George Church planteó este objetivo, que en principio parece técnica, que no moralmente, plausible, pero ante las objeciones que se plantearon reculó y sostuvo que no se le había comprendido bien. Sin embargo, en su libro G. CHURCH, Regenesis, How Synthetic Biology Will Reinvent Nature and Ourselve, Regis 2011, lo volvió a exponer sin dejar lugar a dudas. Parece razonable pensar que si finalmente se lograra crear una célula humana totipotente (proyecto Re-Write), también sería viable hacerlo con ADN neandertal.

Farahany et al., se ha planteado si estos animales deberían ingresar posteriormente en una especie de "santuario", al igual que sucede con los chimpancés después de ser objeto de investigación. N. FARAHANY et al., "The ethics of experimenting with human brain tissue", Nature, vol. 556, April 25, 2018, pp. 429-432.

8 Un informe conjunto del Comité de Bioética portugués y español, dedicado a la biología sintética, analiza precisamente el estatuto ontológico y jurídico de este tipo de hipotéticos mamíferos: "No obstante, de acuerdo con la legislación europea actual, sería aceptable la patente de supuestos mamíferos 'recreados` de forma sustancial. Sin embargo, probablemente entraría bajo la cláusula del límite del orden público y de la moralidad una hipotética

ISSN: 1133-0937

DOI: https://doi.org/10.20318/dyl.2022.6522
DERECHOS Y LIBERTADES

Número 46, Época II, enero 2022, pp. 297-325 
hoc para el que se carece de antecedentes (v. gr., el propio de las Inteligencias Artificiales. El reconocimiento de su personalidad jurídica puede ser un primer paso). ${ }^{9}$

\subsubsection{Casos donde se interviene únicamente en materia inerte}

La casuística aquí también es inabordable, pero podríamos destacar la intervención a nivel atómico y molecular, o en fuentes de energía. En estas investigaciones, los riesgos parecen menos probables que los referidos anteriormente con la materia viva (v. gr., menos viables técnicamente), pero en cualquier caso no inexistentes; además, si se concretaran, los efectos serían aún más drásticos, ya que repercutirían no solo en los seres vivos sino en todo cuanto nos rodea.

Así, el primer ensayo de bomba nuclear (proyecto Manhattan) fue acompañado de una petición de cuasimoratoria ("se deben hacer más estudios", Pamlin\&Armstrong ${ }^{10}$ ) debido a la creencia de que la prueba podía provocar la ignición de toda la atmósfera. Aunque se sabe hoy que este evento es físicamente imposible, ${ }^{11}$ lo que no evita que continúen las suspicacias, a la luz de lo que estamos analizando podría interpretarse a posteriori como una petición de moratoria fallida debido a una creencia (errónea) acerca de un riesgo (inexistente).

Cuando se inauguró el CERN en Suiza se interpuso una demanda ante el Tribunal Europeo de Derechos Humanos para que se paralizase el inicio de la actividad debido a la posibilidad de que se crease un agujero negro. La demanda fue desestimada, pero también podría interpretarse como una petición de moratoria ante un órgano judicial por la creencia, (también) errónea, de la existencia de un riesgo (también) inexistente. ${ }^{12}$

y remota creación de seres humanos, en particular su fase inicial embrionaria." COMITÉ DE BIOÉTICA Y ESPAÑA Y DEL CONSELHO NACIONAL DE ÉTICA PARA AS CIÊNCIAS DA VIDA DE PORTUGAL, La biología sintética. Lisboa-Barcelona. 24 de octubre de 2011.

9 Véase J. GONZÁLEZ, De la persona a la personalidad algorítmica. A propósito de la personalidad jurídica de la Inteligencia Artificial, Ediciones UB, 2000.

10 D. PAMLIN, S. ARMSTRONG, Global Challenges. 12 Risks that threaten human civilisation. The case for a new risk category, Global Challenges Foundation. Future of Humanity Institute, 2015.

11 D. CHUNG, “The Impossibility of Lighting Atmospheric Fire”, Stanford University, 2015.

12 R. JAFFE, W. BUSZA, J. SANDWEISS, F. WILCZEK, "Review of Speculative 'Disaster Scenarios' at RHIC”, Rev. Mod. Phys, vol 72, núm. 4, 2000, pp. 1125-1140.

DERECHOS Y LIBERTADES

ISSN: 1133-0937

Número 46, Época II, enero 2022, pp. 297-325

DOI: https://doi.org/10.20318/dyl.2022.6522 
A pesar de que ninguna moratoria científica planteada sobre este tipo de temáticas ha encontrado acogida, algunos científicos insisten en su necesidad. En concreto, proponen moratorias para aquellas investigaciones donde se creen, desarrollen o modifiquen estados de la materia inexistentes en la Naturaleza o, al menos, en la Tierra (v. gr., conseguir el cero absoluto en nuestro planeta -debido a la radiación del fondo cósmico de microondas, residuo del Big Bang, la temperatura en el espacio es de casi tres grados por encima del cero absoluto-), se logren niveles de energía incompatibles con el Universo, o al menos, con el nuestro (v. gr., densidad crítica); o se creen/descubran partículas teóricas pero no imposibles que pondrían en riesgo todo cuanto conocemos (v. gr., strangelest). ${ }^{13}$

A la hora de comparar estas propuestas de moratoria con las anteriores podemos advertir que: a) son menos reconocibles como eventos posibles; b) nuestra sobreexposición a películas y literatura sobre ciencia ficción nos ha insensibilizado ante determinados riesgos, hasta el punto de trivializarlos; c) cuesta más representarnos cómo son estas partículas, fuentes de energía o estados de la materia. Mientras que todo el mundo puede imaginar un virus peligroso, prácticamente nadie sabe qué es el cero absoluto en el contexto de la medición de la temperatura; d) si fue materialmente imposible convencer al Tribunal de Justicia de la Unión Europea de que las mutaciones causadas con CRISPR son indistinguibles de las naturales, ${ }^{14}$ cabe imaginar cómo recibirían los tribunales de justicia una demanda cuyo objeto fuese la densidad de energía, partículas teóricas o estados de la materia exóticos. Sin embargo, no por ello los riesgos son inexistentes, ni una petición de moratoria puede estar menos justificada.

\subsection{Procedimiento}

Dada la ausencia de un boletín oficial o de un organismo público que lidere una respuesta, las moratorias se convocan a través de tres procedimientos, que a su vez pueden darse de arriba/abajo, o a la inversa.

13 Véase M. REES, Nuestra hora final. ¿Será el siglo XXI el último de la humanidad?, trad. de J. RIERA REY, Crítica, Barcelona. 2004; M. REES, En el futuro. Perspectivas para la humanidad, trad. de J. ROS, Editorial Planeta SA. Crítica, 2019; A. KENT, “Problems with empirical bounds for strangelet production at RHIC", PACS, núm. 23, 2000.

14 Lo comentaremos con más detalle después. Tribunal Superior de Justicia de la Unión Europea (Gran Sala), de 25 de julio de 2018, asunto 528/2016. 
El primer procedimiento es el más formal y, por ende, vinculante. Se realiza a través de una convocatoria en revistas científicas de prestigio, como Nature o Science. En estos casos, quienes firman la petición justifican exhaustivamente su propuesta, a veces de forma un tanto mediática (v. gr., la ingeniería genética podría introducir variantes exóticas en los seres humanos, como "distinguir la luz infrarroja" o desarrollar la capacidad para "degradar ciertas toxinas"), ${ }^{15}$ y establecen también un plazo de vigencia, sin perjuicio de que este pueda después ser prorrogado (v. gr., la moratoria sobre la modificación del virus de la gripe aviar se prorrogó un año). ${ }^{16}$ Obviamente, el formalismo en la petición no conlleva necesariamente su acogimiento (v. gr., la Asamblea Parlamentaria del Consejo de Europa propuso una moratoria para los xenotrasplantes por los riesgos de transmisión de virus a humanos, pero fue sorteado por el Consejo). ${ }^{17}$

El segundo procedimiento no es tan formal, pero va más allá de una simple advertencia o admonición. Se convoca a través de documentos, informes o dictámenes, públicos o privados. A diferencia de la anterior, carecen de un plazo definido y suelen ser propuestas un tanto más vagas, pero a efectos prácticos buscan lo mismo: detener determinadas investigaciones. Por ejemplo, no rebasar el marco de la "agencia o identidad", tanto en las neurotecnologías como en la Inteligencia Artificial, esto es, no realizar investigaciones, experimentos o proyectos donde el ser humano pueda disociar su personalidad o ser objeto de procesos intrusivos en sus mentes (UNESCO; ${ }^{18}$ Yuste et

15 E. LANDER et al., "Adopt a moratorium on heritable genome editing”, Nature, vol. 567, 2019, pp. 165-168.

16 La propuesta inicial fue de sesenta días; después, se prorrogó de forma indefinida, pero finalmente solo duró un año. El objetivo de la moratoria fue doble, paralizar las investigaciones e impedir la publicación de los resultados que mostraban cómo el virus de la gripe aviar, con las modificaciones genéticas adecuadas, podía ser transmisible entre seres humanos. Sin embargo, los resultados se publicaron en Nature y en Science estando vigente aún la suspensión de las investigaciones. Véase R. FOUCHIER, A. GARCÍA SASTRE et al., “Transmission Studies Resume for Avian Flu”, Science, vol. 339 núm. 6119, 1 February. 2013, pp. 520-521.

17 Recomendación 1399/1999, sobre Xenotrasplantes. Asamblea Parlamentaria del Consejo de Europa. 29 de enero de 1999. Solo se lograron unas recomendaciones (véase COUNCIL OF EUROPE. Committee of Ministers. Recommendation. Rec 2003/10 of the Committees of Ministers to member states on xenotrasplantation. Adopted by the Committee of Ministers on 19 June 2003, at the 844 meeting of the Ministers' Deputies).

18 UNESCO. Grupo de expertos ad hoc (AHEG) para la preparación de un proyecto de recomendación sobre la ética de la inteligencia artificial, Primer borrador de Recomendación sobre la Ética de la Inteligencia Artificial, 2020.

DERECHOS Y LIBERTADES

ISSN: 1133-0937

Número 46, Época II, enero 2022, pp. 297-325

DOI: https://doi.org/10.20318/dyl.2022.6522 
al.); ${ }^{19}$ en el caso de la Inteligencia Artificial, tener bajo control los procesos de automejora o autorreplicación y no subestimar su límite superior (Principios de Asilomar para la IA); ${ }^{20}$ prohibir la creación de una IA Fuerte (Federación de Científicos Alemanes); ${ }^{21}$ cuestiones genéricas sobre IA; ${ }^{22}$ limitar las aplicaciones de CRISPR en la línea germinal humana; ${ }^{23}$ no activar genes drivers, en especial, en insectos o en mamíferos, debido a su posible propagación exponencial en el medio ambiente. ${ }^{24}$

En tercer y último lugar, algunas propuestas de moratoria se efectúan a nivel particular con la esperanza de que alguien recoja el guante y la convierta en una moratoria universal (v. gr., clonación terapéutica). En estos casos, son científicos de renombre o especialistas conocedores de una determinada temática que carecen del poder de convocatoria suficiente y se limitan a proponer en qué terreno deben detenerse temporalmente las investigaciones. ${ }^{25}$

19 "A largo plazo, los sistemas de IA podrían desafiar el sentido especial de experiencia y agencia del ser humano" (UNESCO, en Id., Primer borrador, cit.). Yuste et al., lo consideran un "neuroderecho" básico debido a que "caminamos hacia un mundo en el que será posible decodificar los procesos mentales de las personas y manipular directamente los mecanismos cerebrales subyacentes a sus intenciones, emociones y decisiones". R. YUSTE et al., "Four ethical priorities for neurotechnologies and AI", Nature, vol 551, 2017.

20 VV.AA., Asilomar AI principles, Asilomar Conference, Future of Life Institute, 2017.

21 FEDERACIÓN DE CIENTÍFICOS ALEMANES (VDW), Grupo de estudio sobre la Evaluación Tecnológica de la Digitalización, Informe sobre los Principios Asilomar en Inteligencia Artificial, 2018.

22 Un buen ejemplo de este tipo de moratorias sería el documento elaborado colectivamente por autores pertenecientes a instituciones $\mathrm{u}$ organismos dedicados al estudio del riesgo existencial: VV.AA., The Malicious Use of Artificial Intelligence: Forecasting, Prevention, and Mitigation, February, 2018. En dicho informe se recopilan una serie de investigaciones, propuestas u objetivos que no deben ser rebasados.

23 Ejemplos de este tipo de peticiones serían las propuestas del Observatorio de Bioética y Derecho de la Universidad de Barcelona (JSANTALÓ, (coord.), M. CASADO (coord.), M. BOADA, M. CORCOY, I. DE LECUONA, M. LÓPEZ BARONI, G. MARFANY, A. ROYES, Documento sobre Bioética y Edición Genómica en humanos. Observatorio de Bioética y Derecho. Universidad de Barcelona. 2016; de la Academia Nacional de Ciencias alemana en 2015 (en R. HEIDARI, D. MARTIN SHAW, B. SIMONE ELGER, "CRISPR and the Rebirth of Synthetic Biology", Sci Eng Ethics, vol. 23, 2017, pp. 351-363); o de los documentos analizados en I. LECUONA, M. CASADO, G. MARFANY, M. LÓPEZ BARONI, M. ESCARRABILL, "Gene Editing in Humans: Towards a Global and Inclusive Debate for Responsible Research", Yale Journal of Biology and Medicine, 2017, pp. 673-681, todos ellos en relación a las aplicaciones de CRISPR.

24 K. OYE et al., "Regulating gene drivers”, Science, August 08, 2014, pp. 626-628; K. ESVELT, "Conservation demands safe gene drive", PLOS biology, November 16, 2017.

25 Cuando Pauling escribió a Kennedy en 1962 para que cesaran las pruebas atmosféricas de armamento nuclear le advirtió que "muchos científicos, aunque no todos, piensan

ISSN: 1133-0937

DOI: https://doi.org/10.20318/dyl.2022.6522
DERECHOS Y LIBERTADES

Número 46, Época II, enero 2022, pp. 297-325 
A pesar de que podría pensarse, a priori, que carecen de la fuerza suficiente como para ser calificada propiamente de propuesta de moratoria, pueden recorrer el camino inverso, de abajo/arriba, hasta finalizar en efecto en una propuesta formal. Así, estas peticiones individuales pueden acabar registradas en informes o dictámenes y, por último, en una convocatoria universal. La petición de suspender la intervención de la línea germinal humana ha sufrido justo este recorrido inverso. Primero apareció de forma individualizada, a través de las inquietudes formuladas públicamente por algunos de los investigadores más implicados proponiendo parar las investigaciones (v. gr., Emmanuelle Charpentier); ${ }^{26}$ después, en diferentes documentos públicos y privados, (como los que hemos citado); por último, en Nature, con un listado concreto de los principales investigadores en el campo y un plazo definido. ${ }^{27}$

\subsection{Son ajurídicas}

En efecto, los convocantes proceden normalmente del campo de las ciencias; carecen de voluntad alguna de crear una norma jurídica; y a veces, ni siquiera tienen la intención de que se regule a posteriori. El objetivo es detener las investigaciones ipso facto, aunque no haya ninguna sanción prevista para quienes incumplan. Se apela a la prudencia, a la responsabilidad, al espíritu de comunidad trasnacional, o incluso a la mera supervivencia colectiva. En cualquier caso, se observa un cierto orgullo corporativista en las declaraciones de los científicos, una posición de superioridad moral respecto al poder

que es altamente probable que los productos de la fisión radiactiva y el carbono 14 dañen a los humanos que ahora viven, al igual que a los de generaciones futuras, en formas tales que ocasionen leucemia, cáncer de huesos y otras enfermedades" (J. SÁNCHEZ, "Linus Pauling: compromiso con la ciencia y la paz", Investigación y Ciencia, Diciembre, 2020, pp. 80-85). Sobre los experimentos con organoides cerebrales humanos, incluida la posibilidad de su transferencia a los animales, se ha aconsejado que deban "justificarse específicamente", a la espera de una prohibición más genérica, o que al menos exista una cierta proporcionalidad entre los riesgos y los beneficios que se puedan esperar. En S. PORSDAM, R. SUN, G. HERMERÉN, “A framework for the ethical assessment of chimeric animal research involving human neural tissue", BMC Medical Ethics, vol. 20, núm. 9, 2019; y sobre vida artificial, o sobre la posibilidad de crear nanomáquinas que puedan reproducirse en el medio ambiente, Freitas ha planteado que solo se experimente informáticamente. M. REES, en Id., Nuestra hora final, 2004, p. 96, cit.

26 Premio Nobel en 2020, junto a Jennifer Doudna, por su descubrimiento de CRISPR. Véase J. DOUDNA, E. CHARPENTIER, “The new frontier of genome engineering with CRISPR-Cas9", Science, 28 November. vol 346, núm. 6213, 2014.

27 LANDER et al., "Adopt a moratorium on heritable genome editing”, Nature, vol. 567, 2019, pp. 165-168.

DERECHOS Y LIBERTADES

ISSN: 1133-0937

Número 46, Época II, enero 2022, pp. 297-325

DOI: https://doi.org/10.20318/dyl.2022.6522 
político que enarbola la bandera de la autogestión al margen, en realidad, de la sociedad, que no ha tenido la oportunidad de participar porque no ha sido informada a tiempo.

Esta característica no impide que el poder político pueda incentivar una moratoria científica a pesar de disponer los recursos jurídicos adecuados para imponerla. Así, cuando dos equipos de científicos quisieron publicar en Nature y en Science sus investigaciones acerca de cómo modificar el virus de la gripe aviar para que fuese transmisible entre seres humanos, la Administración Obama persuadió, incentivó y conminó cuasicoactivamente a los científicos para que declararan una moratoria, tanto en las investigaciones como en su publicación. A pesar de la larga duración de la misma, ni las revistas implicadas, las dos principales a nivel mundial, ni los investigadores, ni el propio poder político, se atrevieron a forzar la situación con el derecho. Se desconoce qué habría pasado si el caso hubiese acabado en los tribunales, dado que había científicos de diversos países implicados y colisionaban la libertad de investigación, la censura política y la seguridad colectiva. Ante la incertidumbre sobre su poder real para bloquear la investigación, la Administración Obama forzó tanto la moratoria como su prórroga, pero sin salirse nunca del terreno ajurídico. ${ }^{28}$

\subsection{Carecen de mecanismos coercitivos}

Las convocatorias de moratoria distan de ser dictámenes conservadores (v. gr, modificación de la dotación genética humana como herejía contra la naturaleza humana), marxistas (v gr., lucha contra el neoliberalismo globalizado) o proclamas tecnofóbicas, de ahí que, salvo un cierto reproche moral implícito caso de no ser respetadas, las convocatorias carecen de cualquier otro poder coactivo. ${ }^{29}$

En una competición en la que se premia el riesgo, la innovación, el liderazgo, el primer puesto, etc., y donde el ganador se lo lleva todo (v., gr., un

28 Véase "March 29-30, 2012 Meeting of the National Science Advisory Board for Biosecurity to Review Revised Manuscripts on Transmissibility of A/H5N1 Influenza Virus", en D. MALAKOFF, “Breaking News: NSABB Reverses Position on Flu Papers”, Science, 30 March, 2012.

29 Un buen ejemplo fue la convocatoria de Asilomar, donde estuvo ausente el dramatismo o los factores mediáticos o ideológicos. Simplemente, era un llamamiento a la prudencia. C. BERG et al., "Potential Biohazards of Recombinant DNA Molecules”, Science, 26 July, vol 185, núm. 4148, 1974, pp. 303. 
premio Nobel) y el resto ni siquiera aparece en los libros de historia, resulta realmente difícil apelar a la prudencia como única fuerza argumentativa.

Sin embargo, esa es la realidad. Las convocatorias formuladas no suelen ser asesoradas jurídicamente, en el sentido de que no se hace ver que tal investigación o experimento pudiera estar recogido en un tipo penal o incurrir en infracción administrativa. Ni siquiera se apela a los códigos deontológicos. Simplemente se pretende que se paralicen las actividades apelando a la buena fe de los investigadores, bajo el presupuesto implícito de que no se trata de un ardid para ralentizar los avances de los demás. ${ }^{30}$

En el primer congreso internacional sobre CRISPR se adoptó una moratoria tácita, que no expresa, por la que los investigadores se comprometieron a no transferir a una mujer un embrión modificado genéticamente. Aunque se puede citar cierta normativa estatal e internacional al respecto (v. gr., el artículo 13 del Convenio de Oviedo), ${ }^{31}$ la realidad es que existe una zona muy difusa acerca de qué es legítimo y qué no (v. gr., modificación de la línea germinal para curar enfermedades). ${ }^{32}$ Pues bien, cuando el investigador chino que modificó a dos embriones humanos para que fuesen inmunes al SIDA se enfrentó a la comunidad científica, argumentó (erróneamente) que la moratoria de 2015 se había levantado. ${ }^{33}$

30 Aunque en la moratoria de Asilomar participó después la Academia Nacional de Ciencias norteamericana, e incluso hubo un Congreso donde se realizó una convocatoria más formal, asistiendo también juristas (véase J, LARRIÓN, "Historia de las reuniones de Asilomar. Éxitos y fracasos de la autorregulación en las comunidades tecnocientíficas", Sociología y tecnociencia. Revista digital de sociología del sistema tecnocientífico, vol 1, 2020, pp. 63-82), la realidad es que la convocatoria en sí misma la hicieron un grupo de científicos al margen de cualquier administración pública, y nunca perdió su carácter voluntario.

31 Convenio de 4 abril 1997, ratificado por Instrumento de 23 julio 1999. RCL 1999 2638. Instrumento de Ratificación del Convenio para la protección de los derechos humanos y la dignidad del ser humano con respecto a las aplicaciones de la Biología y la Medicina, Oviedo, 4 de abril de 1997.

32 La primera reunión tuvo lugar en Washington entre el 1 y el 3 de diciembre de 2015, y participaron la Academia Nacional de Ciencias, la Academia Nacional de Medicina, ambas norteamericanas, la Sociedad Real de Londres y la Academia de las Ciencias China. Sobre los acuerdos adoptados, véase S. REARDON, "La cumbre sobre edición genética en humanos concluye con opiniones divergentes", Nature, vol. 528, 2015, p. 173.

33 Sobre la dificultad de aceptar una moratoria en esta cuestión, ("una moratoria no es una prohibición para siempre”, G. Church), véase J. SAMPEDRO, “¿Están todos contra los niños CRISPR?", El País, 2 dic, 2018. Además, debemos resaltar que el segundo congreso internacional sobre CRISPR, celebrado en China en diciembre de 2018, no condenó el experimento en sí mismo (modificar dos embriones humanos para que sean inmunes al sida), sino el 
Probablemente sabía que la moratoria, aun tácita, seguía vigente, por lo que le pudieron guiar otros intereses (honor y gloria, como también reconoció más tarde ${ }^{34}$ ). Sin embargo, su argumentación inicial fue de tipo moral, no legal: en 2017 se emitieron determinados informes que indirectamente daban a entender que existía vía libre para la modificación genética de los seres humanos si el objetivo era curar enfermedades. ${ }^{35}$

En resumen, la convocatoria de una moratoria tiene un cierto efecto intimidatorio sobre los científicos que solo puede ser explicable desde la perspectiva de una moral compartida (v. gr., como puede ser no plagiar, no aprovecharse del trabajo de otros, o no falsear los resultados) y con total independencia de la legislación nacional a la que cada uno esté sujeto. Este es el único valor vinculante que tienen estas convocatorias. No es mucho, pero tampoco es nada. El hecho de que en algunos casos se haya respetado al margen del derecho o del poder político nos debe llevar a reconocer una cierta eficacia que no debe ser minusvalorada.

\subsection{Son temporales}

En efecto, una moratoria ad eternum carece de sentido, dado que supondría una paralización de facto de la actividad científica, aun cuando pueda estar justificada (v. gr., no investigar en conciencia artificial). ${ }^{36}$

momento para hacerlo (en el estado actual de la tecnología existe riesgo de mosaicismo y mutaciones off target). Véase On Human Genome Editing II. Statement by the Organizing Committee of the Second International Summit on Human Genome Editing. November 29, 2018.

34 Disponible en "CRISPR babies are real and the scientist who made them sought 'personal fame and fortune'". En https://www.technologyreview.com/the-download/612807/crispr-babies-are-real-and-the-scientist-who-made-them-sought-personal-fame-and/. Consultado 15-12-2020. Véase también A. REGALADO, "Exclusive: Chinese scientist are creating CRISPR babies", MIT Technology Review. November 25, 2018.

35 Para más detalle, véase O. DYER, "Researcher who edited babies' genome retreats from view as criticism mounts", BMJ, November 30, 2018.

36 En una interesante propuesta (Carta Mundial sobre Inteligencia Artificial), Metzinger propone una moratoria sobre conciencia artificial (fenomenología sintética), incluida cualquier posibilidad de confluencia entre neurociencia e IA. Pero su propuesta inicial de moratoria la convirtió a continuación, en el mismo documento, en una petición de prohibición en el ámbito de la UE. Ahora bien, ¿cómo prohibir algo sobre lo que no se ha hecho ningún avance, siquiera mínimo, y que además ni siquiera se sabe si es posible? T. METZINGER, "Hacia una carta mundial sobre la inteligencia artificial", 2018; Sobre el escepticismo ante este tipo de temores, véase P. BENTLEY, "Las tres leyes de la inteligencia artificial: disipar mitos comunes", 2018. Ambos en P. BONCHER, Unidad de Prospectiva Científica (STOA), ¿Debemos temer a la Inteligencia Artificial? Servicio de Estudios del Parlamento Europeo, Marzo, 2018.

ISSN: 1133-0937

DOI: https://doi.org/10.20318/dyl.2022.6522
DERECHOS Y LIBERTADES

Número 46, Época II, enero 2022, pp. 297-325 
El objetivo de una moratoria debe ser dar tiempo a los científicos y los poderes públicos para valorar la gravedad de la situación con objeto de tomar las medidas legales oportunas (v. gr., regular la materia, técnica o experimento objeto de moratoria) o crear los protocolos de seguridad adecuados.

Por ello, la moratoria es de una naturaleza diferente a la de otras fuentes de obligaciones análogas. Así, ciertas recomendaciones sobre la Inteligencia Artificial, como la participación obligada de algún ser humano en decisiones que pongan en peligro la vida, ${ }^{37}$ en técnicas de diagnóstico y tratamiento médico, ${ }^{38}$ materias jurídicas y cuestiones similares; ${ }^{39}$ ciertas prohibiciones, como las referidas a la línea germinal humana (v. gr., prohibición de la eugenesia $^{40}$ ), la clonación reproductiva, ${ }^{41}$ o la no cosificación de los seres humanos, en el caso de las IA, ${ }^{42}$; ciertos derechos; como la posibilidad de saber quiénes son los padres biológicos en el caso de la maternidad subrogada, ${ }^{43}$

37 "En escenarios que involucran decisiones de visa o muerte, debe aplicarse la determinación humana final” (UNESCO, en Id., Primer borrador, cit.); “9.3 La decisión de matar debe ser hecha por seres humanos, y la responsabilidad de la decisión no debe ser transferida a una IA" VV.AA., Montréal Declaration for a Responsible Development or Artificial Intelligence, 2018.

38 UNESCO, en Id., Primer borrador, cit.

39 “(...) derecho a no ser sometidos a una decisión basada exclusivamente en procesos automáticos cuando tal decisión produzca efectos jurídicos sobre los usuarios o les afecte de forma significativa por motivos similares". COMISIÓN EUROPEA. Grupo Independiente de Expertos de Alto Nivel sobre Inteligencia Artificial: Directrices Éticas para una IA Fiable. 2018.

40 Artículo 3 de la Carta de los Derechos Fundamentales de la Unión Europea. Acuerdo de 7 de diciembre 2000. LCEur 2007 2329. DOC 30 marzo 2010, núm. 83.

41 Ídem. También el Protocolo al Convenio de Oviedo. Protocolo de 12 enero de 1998, ratificado por Instrumento de 7 enero 2000, RCL 2001 \540, de Ratificación del Protocolo Adicional al Convenio para la protección de los derechos humanos y la dignidad del ser humano con respecto a las aplicaciones de la biología y la medicina (RCL 1999 \2638, 2822), por el que se prohíbe la clonación de seres humanos, hecho en París el 12 de enero de 1998. BOE 1 marzo 2001, núm. 52, [pág. 7671].

42 Literalmente, dice "objetivadas", pero creo que la palabra correcta es "cosificadas". "Dentro de tales interacciones, las personas nunca pueden ser objetivadas, ni su dignidad debe ser socavada, ni deben violarse o abusarse de los derechos humanos". UNESCO, en Id., Primer borrador, cit. El reciente informe de la Unión Europea opta por un criterio kantiano, pero en un sentido similar: "Seres humanos como sujetos morales, y no como simples objetos que se pueden filtrar, ordenar, puntuar, dirigir, condicionar o manipular". COMISIÓN EUROPEA. Grupo Independiente de Expertos de Alto Nivel sobre Inteligencia Artificial: Directrices Éticas para una IA Fiable. 2018.

43 El Tribunal Constitucional portugués declaró recientemente inconstitucional la ley de maternidad subrogada (STC 225/18) y reconoció el derecho de los menores a conocer sus orígenes biológicos, esto es, quién fue el donante de su materia genético. En España, la ley de 
o si se está interactuando con una IA ("contacto humano significativo"), ${ }^{44}$ etc., pueden superponerse a las causas que justifican una moratoria, pero en última instancia los objetivos no tienen nada que ver con los escenarios indeterminados e imprevisibles a corto plazo de estas.

En conclusión, la moratoria se caracteriza por la provisionalidad, lo que lleva implícito no solo una finalización, sino un plazo corto. Se trata de detener inmediatamente las investigaciones o experimentos hasta que se puedan ponderar los riesgos de continuar.

\section{DELIMITACION CON RESPECTO A OTRAS FIGURAS}

Como hemos expuesto, el supuesto de hecho que puede justificar una moratoria científica coincide con la potencial aplicación del principio de precaución. Sin embargo, este es un principio jurídico consolidado en la legislación, tanto en la nacional como en la internacional, y por ende, susceptible de ser invocado ante un tribunal de justicia.

Así, cuando en su sentencia de 2018 el Tribunal de Justicia de la Unión Europea resolvió que se debía aplicar la normativa europea prevista para los organismos modificados genéticamente a los organismos modificados con CRISPR, ${ }^{45}$ apeló precisamente al principio de precaución. ${ }^{46}$ Más bien fue lo contrario de lo que se puede entender por una moratoria científica, ya que la comunidad investigadora era mayoritariamente contraria a la aplicación de esta normativa. ${ }^{47}$ Sin embargo, el tribunal estimó que la escasez de prece-

reproducción asistida garantiza el anonimato de los donantes (Ley 14/2016), pero existe una fuerte tendencia internacional a reconocer la prevalencia del derecho de los menores como parte del ejercicio de su personalidad.

44 COMISIÓN EUROPEA. Grupo Europeo sobre ética de la ciencia y las nuevas tecnologías, Statement on Artificial Intelligence, Robotics and 'Autonomous' Systems, European Group on Ethics in Science and New Technologies, 2018.

45 En concreto, la Directiva 2001/18/CE del Parlamento Europeo y del Consejo, de 12 de marzo, sobre la liberación intencional en el medio ambiente de organismos modificados genéticamente. DOCE núm. 106, de 17 de abril de 2001, páginas 1 a 39. DOUE-L-2001-80990.

46 El tribunal justificó su sentencia alegando que este tipo de técnicas podían efectuar modificaciones genéticas "a un ritmo y en proporciones que no pueden compararse con las resultantes de la aplicación de métodos convencionales de mutagénesis aleatoria". Tribunal Superior de Justicia de la Unión Europea (Gran Sala), de 25 de julio de 2018, asunto 528/2016.

47 Los motivos de esta discrepancia se pueden agrupar en tres ítems: a) no se puede saber técnicamente si un organismo ha sido modificado con dicha técnica o no; b) las mutaciones que se consiguen con dicha técnica pueden lograrse también por otros procedimientos 
dentes y la magnitud con que dicha técnica podía intervenir en la Naturaleza hacían justificable la extensión del ámbito de extensión de dicha normativa.

Por ello, se podría sostener que el principio de precaución es el reverso de la moratoria científica. Aquel, de naturaleza jurídica, puede invocarse ante un tribunal de justicia y dar lugar a una resolución vinculante para los científicos, lo que presupone un procedimiento administrativo (v. gr., petición de una patente, o de una autorización); esta, la moratoria, puede justificarse por la apelación a la precaución en el sentido coloquial, no jurídico, de la expresión, de ahí que carezca de amparo legal y no vincule a los tribunales de justicia, que en principio no pueden intervenir porque no existe un acto administrativo que les fuerce a resolver.

También hemos de distinguir una moratoria científica de una moratoria judicial. En efecto, cuando el Tribunal de Justicia de la Unión Europea admitió la posibilidad de patentar la partenogénesis de un óvulo humano, estableció una moratoria ciertamente peculiar: se puede patentar siempre y cuando el estado de la técnica no permita generar un ser humano con dicha técnica. Esto es, no se impide la investigación, y ni siquiera el resultado final (conseguir un clon humano, aunque en realidad estaría prohibido por otra normativa, como el protocolo al Convenio de Oviedo sobre clonación, ${ }^{48}$ o el artículo 3 de la Carta de Derechos Fundamentales de la UE), sino la patente sobre la misma. ${ }^{49}$

no sujetos a la directiva europea; c) los investigadores europeos se van a quedar más rezagados frente a sus homónimos chinos y norteamericanos, que son más laxos en estas cuestiones. Véase L. MONTOLIU, Editando genes: recorta, pega y colorea. Las maravillosas herramientas CRISPR, Next DoorPublishers SL, 2018; L. MONTOLIU, “Europa vuelve a perder el tren del progreso y la innovación”, El País, 26 de octubre de 2018; P. PUIGDOMÈNECH, “Cómo regulará Europa las técnicas de edición genética en la agricultura?", Investigación y Ciencia, Septiembre, 2016: DE MIGUEL, en ANSEDE, Manuel, "Modifican ADN de pacientes ciegos con tecnología CRISPR", El País, 20 diciembre 2018.

48 Protocolo al Convenio de Oviedo. Protocolo de 12 enero de 1998, ratificado por Instrumento de 7 enero 2000, RCL 2001\540, de Ratificación del Protocolo Adicional al Convenio para la protección de los derechos humanos y la dignidad del ser humano con respecto a las aplicaciones de la biología y la medicina (RCL 1999 \2638, 2822), por el que se prohíbe la clonación de seres humanos, hecho en París el 12 de enero de 1998. BOE 1 marzo 2001, núm. 52, [p. 7671].

49 En su sentencia de 2011 excluyó la partenogénesis (Tribunal de Justicia de la Unión Europea, Gran Sala. Sentencia de 18 octubre 2011. TJCE \2011 \316), pero en 2014 rectificó y admitió las patentes sobre este tipo de organismos por los motivos y con los límites que hemos explicado (Tribunal de Justicia de la Unión Europea. Sentencia de 18 de diciembre de 2014. asunto C-364/13).

DERECHOS Y LIBERTADES

ISSN: 1133-0937

Número 46, Época II, enero 2022, pp. 297-325

DOI: https://doi.org/10.20318/dyl.2022.6522 
En estos casos de incertidumbre científica (no se sabe cuándo será posible crear un ser humano mediante partenogénesis, y ni siquiera si será posible), los tribunales de justicia establecen una moratoria equivalente a una obligación a término, aunque incierto.

Por último, a veces la comunidad científica invoca el "espíritu de Asilomar", pero no con el objetivo de declarar una moratoria concreta y definida, sino como una forma de convocar a los miembros de determinados campos del conocimiento a analizar las implicaciones éticas de las investigaciones (v. gr., nanotecnología; geoingeniería; bioterrorismo, etc.).$^{50}$ De hecho, algunas veces se confunde lo que sucedió en Asilomar (una moratoria científica) con lo que provocó de forma secundaria (la elaboración de una guía o protocolo de seguridad), con objeto de hacer esto último, pero aprovechando el aura del prestigio de aquella conferencia (v. gr., The Asilomar Convention for Learning Research in Higher Education). ${ }^{51}$

Por ello, estos llamamientos pueden resultar engañosos para la sociedad, alarmando innecesariamente (v. gr., los nanotecnólogos pretenden una moratoria al estilo de Asilomar), cuando en realidad se trata solo de abrir un legítimo proceso de reflexión y se emplea tan significativa denominación para causar un mayor impacto mediático (v gr., no invocarás mi nombre en vano).

\section{LA MORATORIA CIENTÍFICA COMO PRINCIPIO GENERAL DEL DERECHO}

Durante décadas, las tres primigenias comunidades europeas que dieron lugar a la actual Unión Europea carecieron de un listado de derechos fundamentales. ${ }^{52}$ La anómala situación generó bastante incomodidad, dado que por un lado se exigía a los países integrantes y/o candidatos a ingresar en tan selecto club que respetaran los derechos humanos, pero por otro la

50 Por ejemplo, en C. TOUMAY, “An Asilomar for Nanotech”, Nature Nanotechnology, vol 9, July, 2014; E. KINTISHC, “Asilomar 2' Takes Small Steps Toward Rules for Geoengineering", Science, April 02. 2010; Galas, en el contexto del Proyecto Genoma Humano, y Petsko, en el del bioterrorismo -ambos, en G. PETSKO, "An Asilomar moment”, Genome Biology, vol. 3 núm. 10, 2002, pp. 1014.1-1014.3.

51 En M. STEVENS, "An Ethically Ambitious Higher Education Data Science", Research Practice in Assessment, Winter, vol. 9, 2014.

52 Sobre las causas, véase C. PEROTTO, Los derechos fundamentales en la Unión Europea: en busca de un significado, Universidad de Granada, Tesis Doctoral, 2017.

ISSN: 1133-0937

DOI: https://doi.org/10.20318/dyl.2022.6522
DERECHOS Y LIBERTADES

Número 46, Época II, enero 2022, pp. 297-325 
propia UE carecía de su propio documento como punto de referencia. Esto explica los intentos de rebelión de los Tribunales Constitucionales italiano y alemán, que comenzaron a cuestionar el propio ordenamiento jurídico comunitario (casos Frontini y Solange), ${ }^{53}$ o que la propia Unión Europea se planteara cómo adherirse al Convenio Europeo de Derechos Humanos, en el ámbito del Consejo de Europa.

Pues bien, las dos ocasiones en que la UE se ha intentado adherir a dicho Convenio han sido frustradas por el Tribunal de Justicia de la Unión Europea. En efecto, en sendos dictámenes estableció que, si esta propuesta se llevara a cabo, entones el Tribunal de Justicia caería bajo la jurisdicción del Tribunal Europeo de Derechos Humanos, que podría fiscalizar la validez de los actos de las instituciones de la Unión Europea. ${ }^{54}$

No vamos a entrar a valorar aquí el acierto o no de la medida adoptada por el Tribunal de Justicia (la adhesión de la UE al CEDH está prevista incluso en el Tratado de Lisboa ${ }^{55}$ ), ya que nos interesa centrarnos únicamente en la solución adoptada. En efecto, para no privar a los ciudadanos comunitarios de un listado de derechos fundamentales (el carácter vinculante de la Carta no fue efectivo hasta fechas muy recientes, ${ }^{56}$ diciembre de 2009), ${ }^{57}$ el Tribunal de Justicia de la Unión Europea estableció que el Convenio Europeo de Derechos Humanos se aplicaría en calidad de principio general del derecho.

Esta sorprendente calificación (normalmente es al revés, las declaraciones de derechos recogen principios generales del derecho en un sentido

53 S. MUÑOZ, "Los tres niveles de garantías de los derechos fundamentales en la Unión Europea: problemas de articulación", Revista de Derecho Comunitario Europea, núm. 50, 2015, pp. 105-230.

54 Dictamen del Tribunal de Justicia de la Unión Europea. Dictamen 2/94, de 28 de marzo de 1996; Dictamen 2/ 2013 del Pleno del Tribunal de Justicia de la Unión Europea. 18 de diciembre de 2014.

55 Véase la crítica de Martinón a esta posición del Tribunal de Justicia de la Unión Europea. R. MARTINÓN “Los Derechos Humanos en la Unión Europea. En especial, el problema de la adhesión de la Unión al Convenio Europeo de Derechos Humanos", Revista Europea de Derechos Fundamentales, núm. 28, 2015, pp. 49-71.

56 Unión Europea. Carta de los Derechos Fundamentales de la Unión Europea. Acuerdo de 7 de diciembre 2000. LCEur 2007 2329. DOC 30 marzo 2010, núm. 83.

57 La Carta se elaboró primigeniamente con carácter no vinculante (Niza, 2000). La Constitución de 2004 incorporó el contenido a su articulado, pero su fracaso evitó su aplicación obligatoria a todo el territorio UE. Por último, el Tratado de Lisboa ha efectuado una remisión a la Carta, declarando su carácter vinculante para toda la Unión. La UE ha tardado prácticamente sesenta años (el Tratado entró en vigor el 1 de diciembre de 2009) en disponer de su propio documento de derechos humanos.

DERECHOS Y LIBERTADES

ISSN: 1133-0937

Número 46, Época II, enero 2022, pp. 297-325

DOI: https://doi.org/10.20318/dyl.2022.6522 
iusnaturalista. En este caso la DUDH se reconvirtió o transmutó desde el plano del derecho positivo al plano metafísico), permitió una ingeniosa solución: el Tribunal de Justicia de la Unión Europea podría aplicar el Convenio Europeo de Derechos Humanos sin que por ello este formara parte del ordenamiento jurídico positivo de la Unión Europea (forma parte en calidad de principio general del derecho), con lo que se evitaría caer bajo la jurisdicción del Tribunal Europeo de Derechos Humanos (la hipotética adhesión al CEDH hubiese obligado ineludiblemente a aceptar su jurisdicción). De esta forma, los ciudadanos o incluso las instituciones de la UE podrían invocar el CEDH; el Tribunal de Justicia podría emplearlo para resolver los casos que se le presentaran; y a la vez se salvaguarda la singularidad de la Unión Europea como institución política, que no puede ser juzgada por terceros (no hemos de olvidar que Rusia o Turquía forman parte del Consejo de Europa, de ahí también la lógica inquietud del TJUE).

Emplear la expresión "principio general del derecho" para lograr un resultado como el expuesto es en realidad un subterfugio, un ardid que solo se puede dar en derecho, donde determinados conceptos, expresiones e ideas se intercambian una y otra vez (ora son principios, ora valores, ora derecho positivo, ora derecho natural, ora ley eterna "transcrita en el corazón de los hombres", ora prejuicios burgueses "inscritos en la cartera de los capitalistas", ora presupuestos eurocéntricos imperialistas, ora derechos humanos universales, etc.), en función de las requerimientos de cada momento.

Pues bien, dado que analizar la naturaleza jurídica de las moratorias científicas nos introduce en la metafísica (lex prudentiae inscrita en el corazón de los científicos), y que lo que realmente nos importa es cómo lograr su obligatoriedad para los tribunales de justicia, podríamos adaptar la solución del Tribunal de Justicia de la UE a nuestro caso. En concreto, plantearnos que, dados determinados presupuestos, una moratoria científica es un principio general del derecho, y por ende, vinculante para los tribunales si se cumplen determinados requisitos (que analizaremos después). ${ }^{58}$

De esta forma, no haría falta una norma jurídica para que la moratoria fuese vinculante, con lo que se ganaría tiempo; no sería necesario entablar

58 Quizá si algún día contamos con un número suficiente de moratorias científicas podríamos plantearnos el carácter de "costumbre", en el sentido jurídico de la expresión, de dichas moratorias. Pero, por el momento, su número ha sido tan escaso y disperso que estimo que plantearía problemas como fuente del derecho en este caso concreto, de ahí que haya optado por proponer las moratorias como principios generales del derecho. 
un debate social ni político, que enlentecería dramáticamente la adopción de medidas; y podrían tomarse medidas cautelares en tiempo real en función del estado de la tecnociencia contemporánea, estado del que solo podremos enterarnos si la propia comunidad científica nos alerta, no si esperamos a que la clase dirigente, política o jurídica, lo comprenda.

\section{REQUISITOS PARA LA JURIDICIDAD DE UNA MORATORIA CIENTÍFICA}

Atendiendo a las declaraciones de moratoria ya proclamadas o solicitadas en el pasado, podríamos exigir, para que fuesen consideradas equivalentes a un principio general del derecho, y por ende, vinculantes para los tribunales de justicia, lo siguiente:

a) Que fuese convocada en las revistas más relevantes o prestigiosas de ciencias (v. gr., Science, Nature, o equivalente en función de la temática). Con ello, se logra un primer filtro, no solo por el consejo editorial de dichas revistas, sino también por la evaluación anónima de los artículos que se publican.

b) Que fuese convocada por los científicos más relevantes de la temática en cuestión, algo que puede ponderarse por su relevancia en las citas, publicaciones en los últimos años, instituciones a que pertenecen, etc. (v., gr., una propuesta similar a los legitimados para negociar convenios colectivos). Sería razonable exigir que pertenezcan a instituciones de diversos países, para evitar los riesgos, en la medida de lo posible, de la utilización espuria de la moratoria con objeto de librarse de la competencia. ${ }^{59}$

59 Sin duda, el establecimiento de moratorias científicas puede emplearse por motivos espurios, (evitar competencia; tecnofobia; conservadurismo religioso, etc.), de ahí que lo ideal fuese que la adopción de dichas moratorias contase con garantías (v. gr. participación plural e interdisciplinar). Sin embargo, y como pretendo subrayar en el artículo, la singularidad del momento tecnocientífico actual requiere que las decisiones sean ágiles e inmediatas, y los mejor situados son los científicos de la primera línea de las investigaciones. Merece más la pena correr el riesgo de una ocasional utilización abusiva de las moratorias (por eso planteamos la intervención judicial, para minimizar dichos riesgos), que dejarlo todo como está o esperar a que el poder político tome conciencia de cualquier evento disruptivo. La lentitud en la toma de decisiones ante la pandemia nos puede servir de ejemplo de lo que supone tardar en comprender una situación inesperada de ámbito global. 
c) Que haya un plazo definido. Difícilmente sería razonable un plazo superior a cinco años, ${ }^{60}$ dado que en este periodo de tiempo daría tiempo sobrado para convertir una moratoria en una norma jurídica si fuese el caso. Debemos insistir en que una moratoria, en el sentido que estamos tratando, no es una prohibición (v. gr., crear armas bacteriológicas), dado que para algo así ya disponemos de otros instrumentos, como leyes o tratados internacionales, sino una forma de ganar tiempo con una cierta seguridad jurídica.

d) Que responda a riesgos objetivos y definidos, aunque sean improbables. Así, carece de sentido una moratoria sobre Inteligencia Artificial por el riesgo de que esta nos sobrepase en capacidades (v. gr., no sabemos si realmente es posible, y en cualquier caso, es demasiado genérica), pero sería razonable, por ejemplo, una moratoria para no desarrollar neuronas humanas en animales (v. gr., ya es posible, aunque desconocemos sus efectos).

Por otra parte, en lo que se refiere a las cuestiones jurídico/procesales, hemos de plantearnos cómo traducir una convocatoria científica en un procedimiento judicial:

a) Competencia. Resulta razonable exigir que la competencia sea la propia de tribunales a escala estatal (Tribunal Supremo o Audiencia Nacional, en nuestro caso), o internacional. Parece que los únicos tribunales donde sería viable plantearse algo así son la Corte Interamericana de Derechos Humanos, el Tribunal Europeo de Derechos Humanos o el Tribunal de Justicia de la Unión Europea. Aunque son tribunales de composición y naturaleza muy diferente, su jurisdicción sí abarca un número suficiente de entidades estatales donde sería viable imponer la obligatoriedad de una moratoria. La necesidad de agotar la vía nacional antes de acudir a la jurisdicción internacional puede ser razonable cuando la ruptura de una moratoria no supere el territorio de un único Estado. Sin embargo, en un mundo globalizado a veces es difícil ubicar la sede de un experimento o investigación, de ahí que sería necesario crear un procedimiento específico para poder acudir a

60 Es el plazo máximo que se ha observado en algunas peticiones de moratorias (LANDER et al., "Adopt a moratorium on heritable genome editing”, Nature, vol. 567, 2019, pp. 165-168), aunque es verdad que las que se han llevado a cabo realmente no han superado los dos años (v. gr., casos de Asilomar o de la gripe aviar). 
los tribunales internacionales citados sin necesidad de esperar a una resolución de ámbito estatal.

b) La legitimación para acudir a los tribunales deberá venir dada por las administraciones públicas estatales, la fiscalía o equivalente, pero también sería apropiado legitimar a las sociedades científicas, universidades o centros de investigación, ya que pueden conocer de primera mano quiénes realmente quiebran una moratoria ya declarada. Mientras aquellos no dejan de ser medios o instrumentos de poder político, con todo lo que conlleva, las comunidades de científicos pueden valorar con más prontitud no solo qué investigación justifica una moratoria, sino también qué actuación puede romperla.

c) Procedimiento. Dada la celeridad con que debe procederse en estos casos, el procedimiento a seguir debe ser el propio de lo que conocemos como medidas cautelares o cautelarísimas, con objeto de lograr la inmediatez de la cesación de la prosecución de las investigaciones. Recordemos que, si realmente se planteara un supuesto como este, la moratoria científica ya habría sido declarada, de forma que los científicos más implicados en la misma ya habrían valorado suficientemente su necesidad, de ahí que el tribunal solo debería constatar, no la peligrosidad de las investigaciones, sino su prosecución, algo que es mucho menos exigente desde el punto de vista probatorio. Se trata de obligar a toda la comunidad científica a respetar una moratoria científica, no de valorar judicialmente la justificación técnica de la misma.

d) Objeto. La finalidad de una demanda de este tipo debe ser que se requiera a la unidad, centro o investigador que realiza actuaciones encaminadas a romper una moratoria científica para que se abstenga de proseguir con dichas actuaciones. En caso de no cumplirse el requerimiento, se podrían instar medidas coercitivas.

Sin duda, la restricción de un bien jurídico tan fundamental como la libertad de investigación en su doble manifestación, como derecho de la comunidad científica y como derecho de la sociedad a beneficiarse de dichas investigaciones, plantea problemas teóricos en los límites del Estado de Derecho. Sin embargo, hemos de recordar que los derechos fundamentales no son absolutos, sino que hay que confrontarlos caso por caso (v. gr., derecho a la información versus derecho a la intimidad). Por ello, estimamos que el derecho a la libertad de investigación debe ceder, en determinados casos, 
frente al derecho a la vida, a la integridad física o al medio ambiente de la sociedad. De hecho, así está establecido en la legislación positiva, donde se han prohibido expresamente determinadas investigaciones (v. gr. modificar la línea germinal humana; clonación reproductiva; híbridos interespecíficos en determinados casos), por los motivos más variopintos, desde la invocación a la dignidad humana hasta los riesgos sociales y medioambientales de dichas investigaciones. Esto es, el derecho a la libertad de investigación no goza de un rango superior al de otros valores, de ahí que pueda restringirse; cuestión diferente es el instrumento jurídico en concreto que se emplee para limitar, no solo este derecho, sino cualquier derecho fundamental.

Pues bien, precisamente para solventar las posibles objeciones formales que se pudieran plantear en los supuestos analizados en este trabajo (v. gr., básicamente, y en el caso concreto de nuestro país, la ausencia de una ley orgánica que sirva de cobertura para una limitación tan drástica), hemos propuesto una intervención judicial, garante última, por tanto, de los derechos fundamentales (algo parecido a como ha sucedido con la pandemia que nos azota, cuya gravedad se ha considerado suficiente para confinamientos perimetrales sin estado de alarma, pero con la intervención judicial). ${ }^{61}$

El problema de fondo que nos planteamos en el presente artículo es cómo hacer frente a situaciones generadas por la tecnociencia contemporánea para las que carecemos de antecedentes y de margen de maniobra, esto es, cuando no solo no hay normativa aplicable, sino que no da tiempo a tramitarla. Una opción es no hacer nada y seguir como ya estamos, opción que precisamente denunciamos en este artículo por imprudente; una segunda opción es crear una norma ad hoc que sirva de amparo para este tipo de actuaciones, opción que también denunciamos, pero por ingenua (¿quién convence al poder político de esta necesidad?); la tercera opción, defendida en este artículo, es disponer de al menos un instrumento jurídico con los requisitos mínimos

61 Resulta interesante recordar cómo el primer confinamiento que se generó como consecuencia de la pandemia, en Haro (La Rioja), el 3 de marzo, no tuvo "ningún ropaje jurídico, o por lo menos no dotado de publicidad" A. NOGUEIRA “Confinar el coronavirus. Entre el viejo derecho sectorial y el derecho de excepción", El cronista del Estado Social y Democrático de Derecho, 86/87, 2020, pp. 22-31 o cómo el Tribunal Superior de Justicia de Galicia apeló a la "ponderación de bienes" para suspender el derecho de manifestación durante la pandemia (a pesar de la oposición de la fiscalía) sin la cobertura del Real Decreto de estado de alarma (si dicha suspensión -o limitación, no entramos ahora en ese debate- hubiese estado cubierta por dicho Real Decreto, no habría podido entrar a conocer del asunto), simplemente porque estaba en juego la vida. (Sala de lo Contencioso Administrativo de 28 de abril de 2020. Sentencia 136/2020. RJCA, 2020, 457). 
para que una moratoria sea universalmente obligatoria, aunque solo sea en nuestro ámbito territorial, nacional o europeo, en un contexto tecnocientífico imparable e impredecible como el presente.

\section{CONCLUSIONES}

A diferencia del Convenio de Oviedo, la Declaración Universal sobre Bioética y Derechos Humanos carece de la fuerza vinculante de un tratado internacional. Sin embargo, su valor simbólico es innegable, de ahí que sea legítimo plantearse si sus propuestas deben convertirse en obligaciones jurídicas erga omnes. A mi juicio, del contenido de los artículos citados al principio de este trabajo se desprende el mandato de tomar las medidas adecuadas para proteger a las generaciones futuras, la biosfera, $\mathrm{y}$, en último término, la vida misma en el planeta. Por ello, acoger las moratorias científicas en nuestros ordenamientos jurídicos supondría un instrumento eficaz para dar cumplimiento a los objetivos últimos de dicha Declaración.

Por otra parte, son de sobra conocidos los principios de la bioética (autonomía, justicia, beneficencia y no maleficencia), que se han ido extendiendo y adaptando a otras disciplinas, como la Inteligencia Artificial, donde se han ampliado (explicabilidad, XAI), ${ }^{62}$ las neurotecnologías (agencia, Yuste et al.), ${ }^{63}$ o la genética (v. gr., genoma humano como patrimonio de la humanidad, UNESCO). ${ }^{64}$ Pues bien, por mi parte plantearía como un principio in-

62 Como sostienen los autores que han recopilado los principios éticos a la Inteligencia Artificial, no debería sorprender, dado que muchos problemas se superponen. De hecho, los 47 principios que han recopilado de los documentos más relevantes sobre esta temática los han reducido a manifestaciones de los cuatro ya existentes en bioética, añadiéndole solo el de "explicabilidad", que englobaría "inteligibilidad" y "responsabilidad" (L. FLORIDI et al., "A14People - An Ethical Framework for a Good AI Society: Opportunities, Risks, Principles, and Recommendations", Minds and Machines, vol. 28, 2018, pp. 689-707. También es de reseñar que el único principio genuinamente propio de la Inteligencia Artificial, la "explicabilidad", sea al mismo tiempo el único no viable debido al problema de la Caja Negra, que además repercute en el ejercicio de otros derechos ya reconocidos (v. gr., en el Reglamento de Protección de Datos de la UE), hasta el punto de hacerlos inviables.

63 Unión Europea. Carta de los Derechos Fundamentales de la Unión Europea. Acuerdo de 7 de diciembre 2000. LCEur 2007 2329. DOC 30 marzo 2010, núm. 83.

64 Artículo 1. El genoma humano es la base de la unidad fundamental de todos los miembros de la familia humana y del reconocimiento de su dignidad intrínseca y su diversidad. En sentido simbólico, el genoma humano es el patrimonio de la humanidad. Declaración Universal sobre el Genoma Humano y los Derechos Humanos. 11 de noviembre de 1997.

DERECHOS Y LIBERTADES

ISSN: 1133-0937

Número 46, Época II, enero 2022, pp. 297-325

DOI: https://doi.org/10.20318/dyl.2022.6522 
herente a la temática que estamos tratando el "principio de reversibilidad", esto es, que los experimentos que se puedan realizar con las tecnociencias no puedan nunca superar un umbral a partir de cual, suceda lo que suceda, no cabría dar marcha atrás porque estaría fuera del control humano. Es cierto que no podemos "des-inventar" ni "des-des-cubrir" la energía atómica o la ingeniería genética (y tampoco queremos). Pero sí podemos tomar medidas para impedir cualquier acción que pueda poner en peligro potencialmente el contexto vital y material donde coexisten los seres humanos y el resto de seres vivos, empleando criterios lo más objetivos, rigurosos y realistas posibles. Sin estas medidas, solo cabe cruzar los dedos y desearnos suerte (con estas medidas, también, pero al menos nos damos alguna oportunidad).

Las moratorias científicas serían una consecuencia de este principio. Por lo pronto, es un hecho indubitado que no constituyen una cuestión meramente teórica ni académica debido a que se convocaron en el pasado y se seguirán convocando en el futuro. La cuestión clave estriba en si los juristas nos vamos a dar alguna vez por aludidos para poder enfrentarnos a lo que supone convivir con la hipotética aparición de los denominados "cisnes negros". ${ }^{65}$

Podemos optar por seguir como hasta ahora, esto es, no tenerlas en cuenta desde un punto de vista jurídico. Resultaría una posición bastante cómoda: los jueces solo aplican el derecho positivo aprobado por el poder legislativo sin quebrarse más la cabeza con situaciones para las que nadie está preparado. De esta forma, las moratorias seguirían siendo algo exótico para el Derecho, una boutade de científicos encandilados por los movimientos asamblearios y la autogestión.

Por el contrario, la propuesta que formulamos pretende afrontar una realidad: la tecnociencia contemporánea exige recursos jurídicos para poder resolver con inmediatez una situación sobrevenida; y carecemos de dichos recursos. El hecho de que se declaren o propongan moratorias lo debemos tomar como una señal o advertencia de que el Derecho no alcanza, que los poderes públicos son demasiado lentos para tomar decisiones; que determinadas investigaciones exigen decisiones inmediatas, sobre la marcha, que

65 “Un evento de tipo 'cisne negro' es un suceso muy poco frecuente, aunque con elevado impacto; tan raro, que puede que ni siquiera sea observado. Por tanto, la probabilidad de que ocurra normalmente solo puede estimarse con un alto grado de incertidumbre", COMISIÓN EUROPEA. Grupo Independiente de Expertos de Alto Nivel sobre Inteligencia Artificial, Directrices Éticas para una IA Fiable, 2018. 
no pueden ser demoradas; y que los riesgos son enormes. Nuestros ordenamientos jurídicos están adaptados a la tercera revolución industrial, un contexto donde lo más peligroso son las armas nucleares, bacteriológicas, etc., esto es, un contexto donde las variables son relativamente predecibles. Sin embargo, nunca nos habíamos planteado que se pudiera intervenir en los seres vivos como ahora parece plausible, ni que tuviéramos que lidiar con potenciales entidades biológicas, artificialmente creadas, que superan el tamaño, y por ende, las capacidades de replicación y/o reflexión, de los microorganismos.

Cualquiera que se adentre en el estado de la tecnología contemporánea podrá comprobar la discordancia existente entre nuestros ordenamientos jurídicos y la celeridad con que avanzan las investigaciones. Términos como CRISPR, biobots, redes convolucionales, Caja Negra, biobricks, genes drivers, moléculas dextrógiras, etc., tan comunes en ciencias, no arrojan ningún resultado en las bases de datos jurídicas a pesar de las enormes implicaciones que pueden tener para nuestras sociedades. Determinados proyectos no están ni permitidos ni prohibidos porque nadie sabe que se han planteado; y no porque sean investigaciones secretas, dado que aparecen en las principales revistas científicas, sino simplemente porque son tan extravagantes que nos parece innecesario regularlos antes de tiempo; o porque sencillamente no comprendemos sus implicaciones debido a que no sabemos distinguir la ciencia ficción de la tecnociencia potencialmente posible. Nuestro razonamiento colectivo es: cuando llegue el momento, se creará la normativa adecuada empleando los cauces formales tradicionales; y si llegamos tarde, los daños no serán tan cuantiosos ni tan irreversibles como para no poder asumirlos colectivamente. ${ }^{66}$

En biomedicina, lo ideal sería no modificar la línea germinal humana, pero ya se ha hecho; en ingeniería genética, lo ideal sería poder saber cuándo

66 El retraso del derecho con respecto a los avances tecnocientíficos está siendo denunciado en numerosos informes (véase FEDERACIÓN DE CIENTÍFICOS ALEMANES (VDW), Grupo de estudio sobre la Evaluación Tecnológica de la Digitalización, Informe sobre los Principios Asilomar en Inteligencia Artificial, 2018; W. GRANT, "Minimizing global catastrophic and existential risks from emerging technologies through international law", Virginia Environmental Law Journal, vol. 31, 2013: G. MARCHANT, "The growing gap between emerging technologies and the law", en G. MARCHANT et al., The Growing Gap Between Emerging Technologies and Legal-Ethical Oversight, Springer, 2011, pp. 19-33; AMERICAN ASSOCIATION FOR THE ADVANCEMENT OF SCIENCE; FEDERAL BUREAU OF INVESTIGATION; UNITED NATIONS INTERREGIONAL CRIME AND JUSTICE RESEARCH INSTITUTE, National and Transnational Security Implications of Big Data in the Life Sciences. 2014).

DERECHOS Y LIBERTADES

ISSN: $1133-0937$

Número 46, Época II, enero 2022, pp. 297-325

DOI: https://doi.org/10.20318/dyl.2022.6522 
un ente biológico ha sido modificado genéticamente, pero ya no se puede saber, ni aunque sea un embrión humano (v. gr., CRISPR); en Inteligencia Artificial, lo ideal sería no crear algoritmos que incumpliesen el principio de "explicabilidad", pero ya se crean, y además, son los más prometedores (v. gr., Caja Negra); en neurología, lo ideal sería que las neuronas humanas no interactuasen con las de animales, pero ya se hace. Simplemente, estamos llegando tarde.

Sin embargo, el peor escenario para la sociedad no es que el Derecho llegue tarde, sino que simplemente ya no sea necesario. Nadie se planteó regular la energía nuclear hasta que vimos dos ciudades desaparecer en segundos; y la podemos regular porque afortunadamente quien predijo la ignición de la atmósfera terrestre se equivocó. Si los científicos están aprendiendo a reescribir la materia viva y la inerte, los juristas debemos estar a la misma altura a la hora de poder tomar decisiones. Sin caer en fatalismos tecnofóbicos, pero sin sobrestimar nuestra capacidad de reacción ante eventos que ni siquiera podemos imaginar que sean posibles.

\author{
Manuel Jesús López BARONI \\ Universidad Pablo de Olavide \\ Carretera de Utrera 1 \\ 41013. Sevilla \\ e-mail:mjlopbar1@upo.es
}

